\title{
Thermal Shock Behaviour of Angle-Ply and Woven Dense Ceramic-Matrix Composites
}

\author{
C. KASTRITSEAS, P. A. SMITH, J. A. YEOMANS \\ School of Engineering (H6), University of Surrey, Guildford, Surrey GU2 7XH, UK
}

\begin{abstract}
The behaviour of two Nicalon/calcium aluminosilicate ceramic composite laminates $\left(\mathrm{a}\left( \pm 45^{\circ}\right)_{3 \mathrm{~s}}\right.$ and a plain-weave woven) under conditions of thermal shock has been studied. Test specimens heated at various temperatures were quenched into room-temperature water. This was followed by detailed damage characterisation. In addition, post-shock mechanical properties were assessed by tensile tests (for the woven laminate) and flexural tests (for both laminates). Both materials were found to have comparable thermal shock resistance. Crack morphologies comprised matrix cracks of various orientations that exhibited similar characteristics to those described for thermally shocked cross-ply laminates with the same constituents, but cracking was found to be less widespread in the woven laminate. Fibre breaks were also detected on the woven material when high-temperature degradation of the fibre-matrix interface was present. A gradual reduction in properties (stiffness, proportional limit stress, fracture strength) of thermally shocked specimens was identified, which began at larger shocks than those at which thermal shock damage initiated. This was attributed to the extension of some matrix cracks into the bulk of material.
\end{abstract}




\section{INTRODUCTION}

Thermal shock, i.e. a sudden temperature change $(\Delta T)$, is a potentially detrimental condition for the integrity of ceramic-based materials. The worst condition develops when a heated material comes into contact with a medium of much lower temperature (cold shock). In this case, tensile stresses develop at the material surface where they can cause the propagation of a range of pre-existing flaws ${ }^{1}$. Monolithic ceramics can be designed to withstand large shocks without fracturing, but their low fracture toughness makes them susceptible to severe property degradation or even catastrophic failure after crack onset. In contrast, fibre-reinforced ceramic-matrix composites (CMCs) do not fail catastrophically even after being subjected to very large shocks. However, they can still exhibit mechanical and thermal property degradation, especially when the shock follows prolonged high temperature exposure that induces microstructural changes (e.g. embrittlement of the fibre-matrix interface) ${ }^{2}$.

The behaviour of 2-D SiC/SiC CMCs is affected by the large pores inherent in their microstructure, which act as crack initiators at moderate shocks ${ }^{3,4}$. Dense CMCs (mostly of glass- or glass ceramic-matrix) reinforced with continuous unidirectional (UD) fibres, as well as the plies of cross-ply laminates that contain longitudinal fibres, exhibit multiple matrix cracking perpendicular to the fibres (PMCs) that leaves them unaffected $^{5-10}$. In contrast, the end faces of UD CMCs and the transverse plies of crossply materials suffer so-called 'thermal debond' 11 or 'horizontal matrix cracks' (HMCs) ${ }^{10}$ that run along the face/ply length, being continuously deflected at successive fibre-matrix interfaces $6,8,10,11$. Such damage always originates at, or close to, the centreline of the face under investigation in water-quench tests ${ }^{6,10}$. On application of higher shocks, PMCs multiply in number but remain surface features while HMCs extend significantly in length and depth $5,6,10$. In addition, although damage 
accumulates in every ply for increasing shock severity, it is always more extensive the closer a ply is located to the centreline of the face ${ }^{10}$.

In this article, experimental work is extended to dense angle-ply and woven fibrereinforced $\mathrm{CMCs}$ as the behaviour of $\left( \pm 45^{\circ}\right)_{3 \mathrm{~s}}$ and plain-weave (PW) woven Nicalon/calcium aluminosilicate laminates is studied. The results presented include determination of thermal shock resistance, description of the relevant damage modes and assessment of the post-shock mechanical properties of the materials.

\section{MATERIALS AND EXPERIMENTAL TECHNIQUES}

\subsection{Material}

Two plates of CMC that comprised Nicalon fibres in a calcium aluminosilicate (CAS) matrix were supplied by Rolls-Royce plc. Although the nature of the matrix material was not investigated in this study, a previous study ${ }^{12}$ of cross-ply material from the same source had shown it to be almost entirely anorthite $\left(\mathrm{Ca}_{2} \mathrm{Al}_{2} \mathrm{Si}_{2} \mathrm{O}_{8}\right)$ with a small quantity of alumina particles and very fine zirconia particles. The first plate had a $\left( \pm 45^{\circ}\right)_{3 \mathrm{~s}}$ configuration and the second a plain-weave woven structure. The thickness of each plate was $\sim 2.1 \mathrm{~mm}$ and the fibre volume fraction was equal to 0.34 . Both plates were cut using a water-cooled diamond saw into specimens with dimensions $6 \mathrm{~mm} \mathrm{x}$ $6 \mathrm{~mm} \times 2.1 \mathrm{~mm}$ and $50 \mathrm{~mm} \times 5 \mathrm{~mm} \times 2.1 \mathrm{~mm}$ for damage observation and mechanical testing, respectively. Longitudinal faces $(6 \mathrm{~mm} \times 2.1 \mathrm{~mm}$ or $50 \mathrm{~mm} \times 2.1 \mathrm{~mm})$ were initially ground using silicon carbide paper with grain size 320-4000 grit to reveal the microstructure, and were subsequently polished using diamond paste to a $1 \mu \mathrm{m}$ finish. 
The microstructures of both materials can be seen in Figure 1. In the angle-ply laminate, the individual plies can be clearly distinguished but there is uneven fibre distribution that results in the appearance of some matrix-rich regions. The surface of the woven laminate consists of three different areas: areas that contain longitudinal fibres, areas that contain transverse fibres, and zones with only matrix material present. If the undulating nature of all the above areas is neglected, the woven material can be described as a laminate that contains three different, alternating types of 'ply': $0^{\circ}$ plies (i.e. plies with longitudinal fibres), $90^{\circ}$ plies (i.e. plies with transverse fibres), and pure matrix plies.

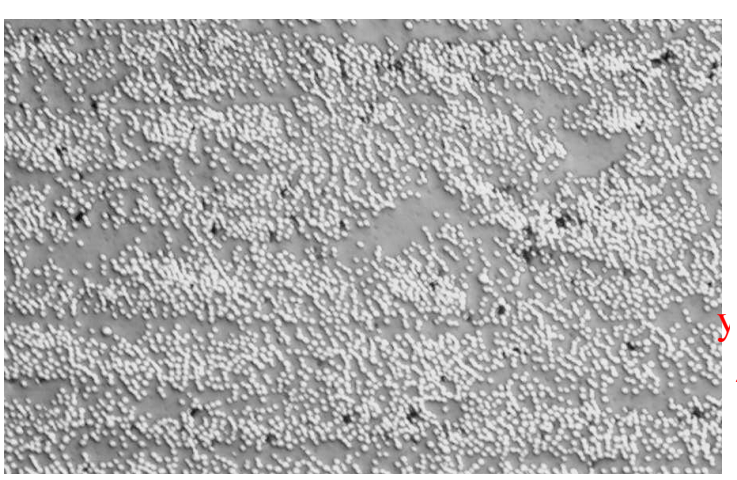

(a)

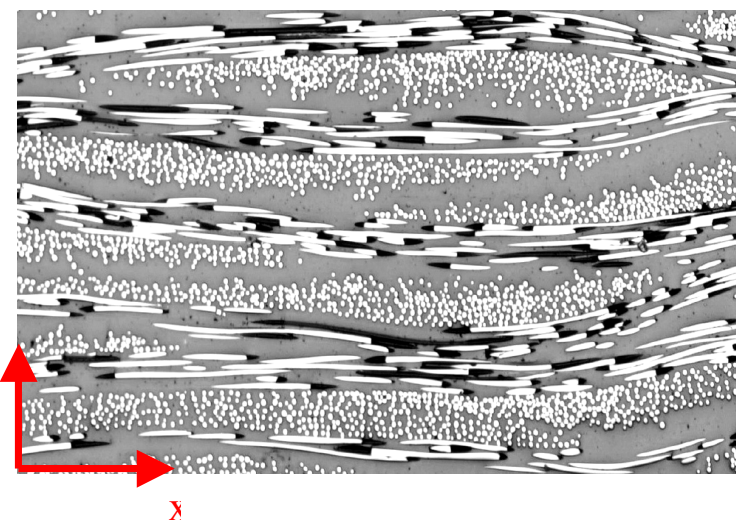

(b)

Fig. 1. The surface of (a) $\left( \pm 45^{\circ}\right)_{3 \mathrm{~s}}$, and (b) PW woven Nicalon/CAS CMC as seen using reflected light microscopy. The fibre diameter is $\sim 15 \mu \mathrm{m}$.

\subsection{Experimental Techniques}

\subsubsection{Thermal Shock Test Method and Damage Observation}

The water-quench test was employed to produce the thermal shock condition while microscopic examination of the shocked specimens was carried out using reflected light microscopy (RLM) and scanning electron microscopy (SEM). Details of the procedures followed to perform the thermal shock tests and the methods used for crack identification and density measurement are given in detail elsewhereb ${ }^{10}$. It should be 
noted that, as in Kastritseas et al. ${ }^{10}$, specimens tested at the highest $\Delta T \mathrm{~s}(\Delta T=700$, $\left.800^{\circ} \mathrm{C}\right)$ were soaked in the furnace for shorter times $(5-7$ mins) than those heated at lower temperatures (15-20 mins) to avoid microstructural degradation and, thus, concentrate the study only on the effects of thermal shock treatment. However, some samples for damage observation were indeed examined after longer high-temperature exposure and the results are reported below.

\subsubsection{Mechanical Testing}

\subsubsection{Tensile Testing}

Shocked specimens of the PW woven material were tested in tension. Aluminium end tabs were bonded to the ends of test coupons using a Permabond F246 rubber toughened acrylic adhesive, leaving a final gauge length of $30 \mathrm{~mm}$. The applied strain was measured using a Vishay Micro-Measurements CEA-06-250UN-350 precision strain gauge, which was attached to the centre of one of the large faces $(50 \mathrm{~mm} \mathrm{x}$ $5 \mathrm{~mm}$ ) of the test coupon using a cyano-acrylate adhesive. The output of the strain gauge was recorded using a Solartron SI 3535D data logger. Tensile tests were carried out using an Instron model 1195 tensile testing machine with a $100 \mathrm{kN}$ load cell at a cross-head speed of $0.5 \mathrm{~mm} / \mathrm{min}$. All samples were loaded continuously to failure. The load and strain outputs were stored as data files in a PC running Windows ${ }^{\mathrm{TM}}$ software, which was connected to the Instron machine and the digital strain indicator. Processing of the recorded data was performed using Microsoft Excel ${ }^{\mathrm{TM}}$ software. Mechanical properties were determined from the generated graphs (two specimens at each $\Delta T$ ) following ASTM C1275-95 and BS EN 658-1:1998 where appropriate.

\subsubsection{Flexure Testing}


Flexure testing was performed on shocked specimens of both configurations using a three-point bend test rig that had been designed and built in-house. Although four-point bending gives a more uniform stress state, insufficient material was available for this configuration to be used. Further, three-point bending is adequate fr comparative purposes, as required here. The support span was $32 \mathrm{~mm}$. The upper platen, that contained the two supports on which the test specimen was placed, was firmly pinned to an Instron 1175 Testing Machine. The lower platen, which had the central loading point fixed on it, was attached to the cross-head beam of the testing machine. A $10 \mathrm{kN}$ load cell was employed. The output of the load cell and the cross-head displacement were monitored in real-time and recorded by a PC running Windows ${ }^{\mathrm{TM}}$ software. The flexural testing procedure and the analysis of the results were performed following closely the ASTM C 1341-97 Standard Test Method using data generated after testing two specimens at each $\Delta T$.

\section{RESULTS}

\subsection{Damage Characterisation}

Two modes of damage were identified, namely 'matrix cracks' and 'fibre failures'. Following Kastritseas et al. ${ }^{10}$, matrix cracks can be further divided into horizontal matrix cracks (HMCs) and perpendicular matrix cracks (PMCs) if the orientation of the cracks relative to the horizontal direction (x-axis) is taken into account. 


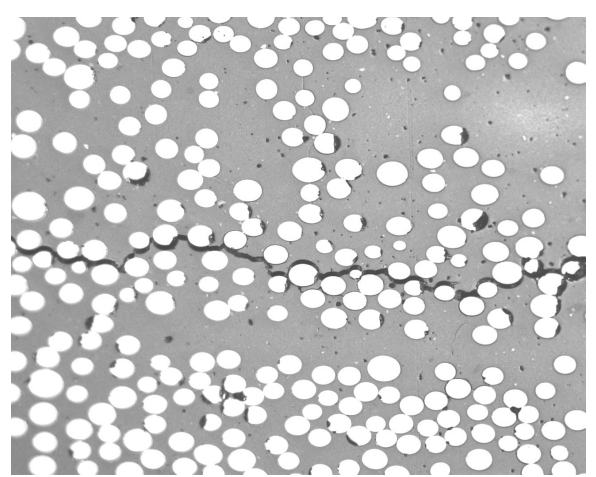

(a)

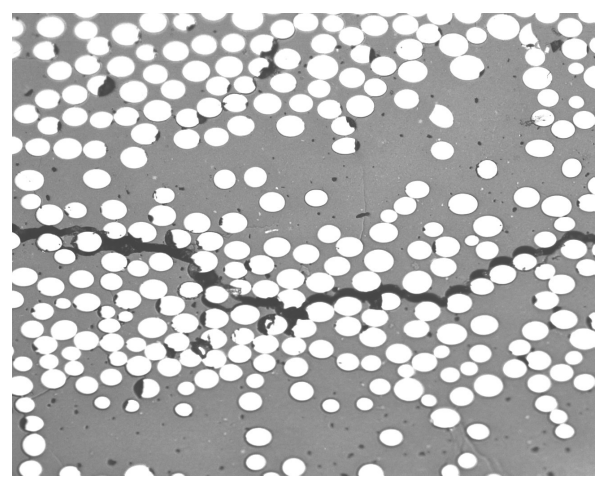

(b)

Fig. 2. Reflected light microscopy (RLM) images of horizontal matrix cracks (HMCs) on $\left( \pm 45^{\circ}\right)_{3 \mathrm{~s}}$ laminates at (a) $\Delta T=500^{\circ} \mathrm{C}$, and (b) $\Delta T=800^{\circ} \mathrm{C}$

The $\left( \pm 45^{\circ}\right)_{3 \mathrm{~s}}$ laminate developed mainly HMCs (Figure 2(a)) that appeared at $\Delta T_{\mathrm{c}} \approx 450^{\circ} \mathrm{C}$. These cracks were located towards the centreline of the face and seemed to be associated with small pores or voids. Cracks were also observed at some matrix-rich regions but were random, small in number and extent. HMCs grew in length and depth (Figure 1(b)) at higher $\Delta T$ s but not in number. At the highest shocks, 2 or 3 deep cracks could be seen that traversed the face from edge to edge close or along the centreline accompanied by a small number of shallower HMCs spread across the surface of the face.

In the PW woven Nicalon/CAS laminate, PMCs were the first form of damage observed at $\Delta T_{\mathrm{c}}=400^{\circ} \mathrm{C}$. They ran through pure matrix plies at or close to the centreline of the surface and arrested upon encountering fibres in adjacent plies (Fig. 3(a)). Similar independent cracks were observed at the same $\Delta T$ inside individual $0^{\circ}$ plies, which were short in length and span the matrix between adjacent fibres (Fig. 3(b)). HMCs appeared at $\Delta T=450^{\circ} \mathrm{C}$ in $90^{\circ}$ plies located towards the centreline of the face. They originated from either the edges of the specimen or pre-existing damage (e.g. voids) and were normally contained within the $90^{\circ}$ plies (Fig. 3(c)). At high temperature differentials $\left(\Delta T=700-800^{\circ} \mathrm{C}\right)$ and on samples heated for longer times (15-20 mins) fibre failures 
appeared, as some PMCs did not get deflected or arrest upon encountering a fibrematrix interface (Fig. 3(d)).

With increasing shock severity, PMCs multiplied in number until for $\Delta T \geq 600^{\circ} \mathrm{C}$ they were spread throughout the surface. In addition, although they increasingly penetrated into adjacent plies, their depth and opening showed a very small increase, i.e. they remained shallow and narrow surface features. At the same time, HMCs became deeper and more widespread, and could be seen crossing into other plies to the extent that, in some specimens quenched at $\Delta T=800^{\circ} \mathrm{C}$ after being soaked for longer times, individual cracks along the centreline of the surface connected to form a major, deep crack that traversed the face from edge to edge.

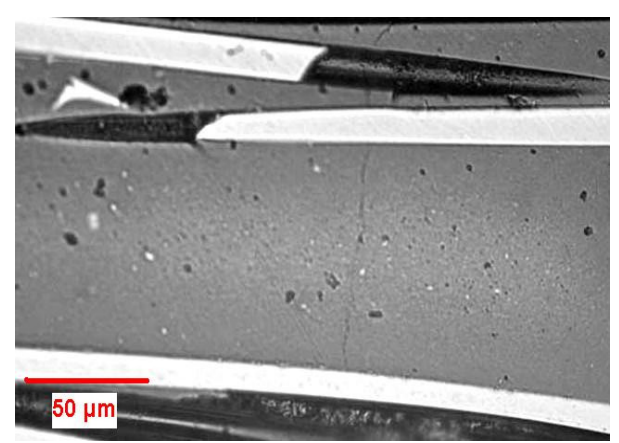

(a)

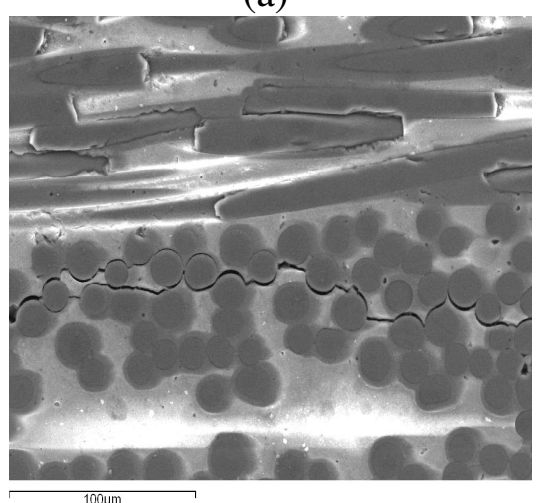

(c)

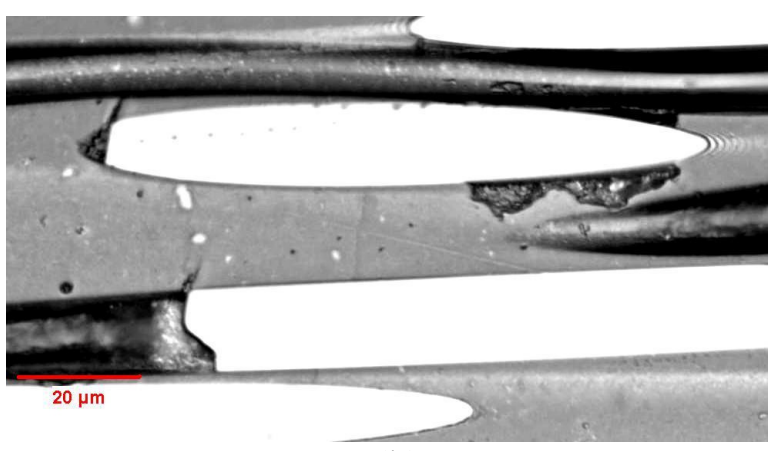

(b)

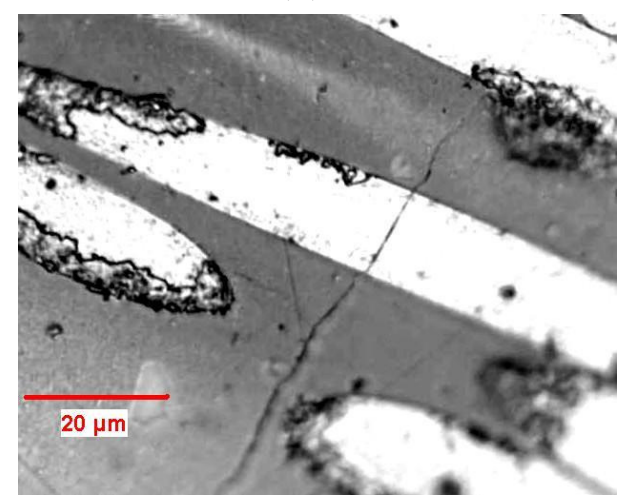

(d)

Fig. 3. (a) Perpendicular matrix cracks (PMCs) running between two $0^{\circ}$ plies of the PW woven laminate (RLM image) (b) PMC inside a $0^{\circ}$ ply of the PW woven laminate (RLM image) (c) Scanning electron microscopy (SEM) image of HMC inside a $90^{\circ}$ ply of the PW woven laminate (d) Fibre fracture due to the propagation of a PMC at $\Delta T=800^{\circ} \mathrm{C}$ on the surface of sample soaked for longer time. Oxidation of the fibrematrix interface is evident. (RLM image) 
Both PMC and HMC densities increased continuously up to the highest $\Delta T$, but the density of PMCs was always higher than that of HMCs, with the difference between the two getting larger (Figure 4). In addition, higher PMC densities as well as longer and deeper HMCs could be observed in the plies located towards the centreline of the face.

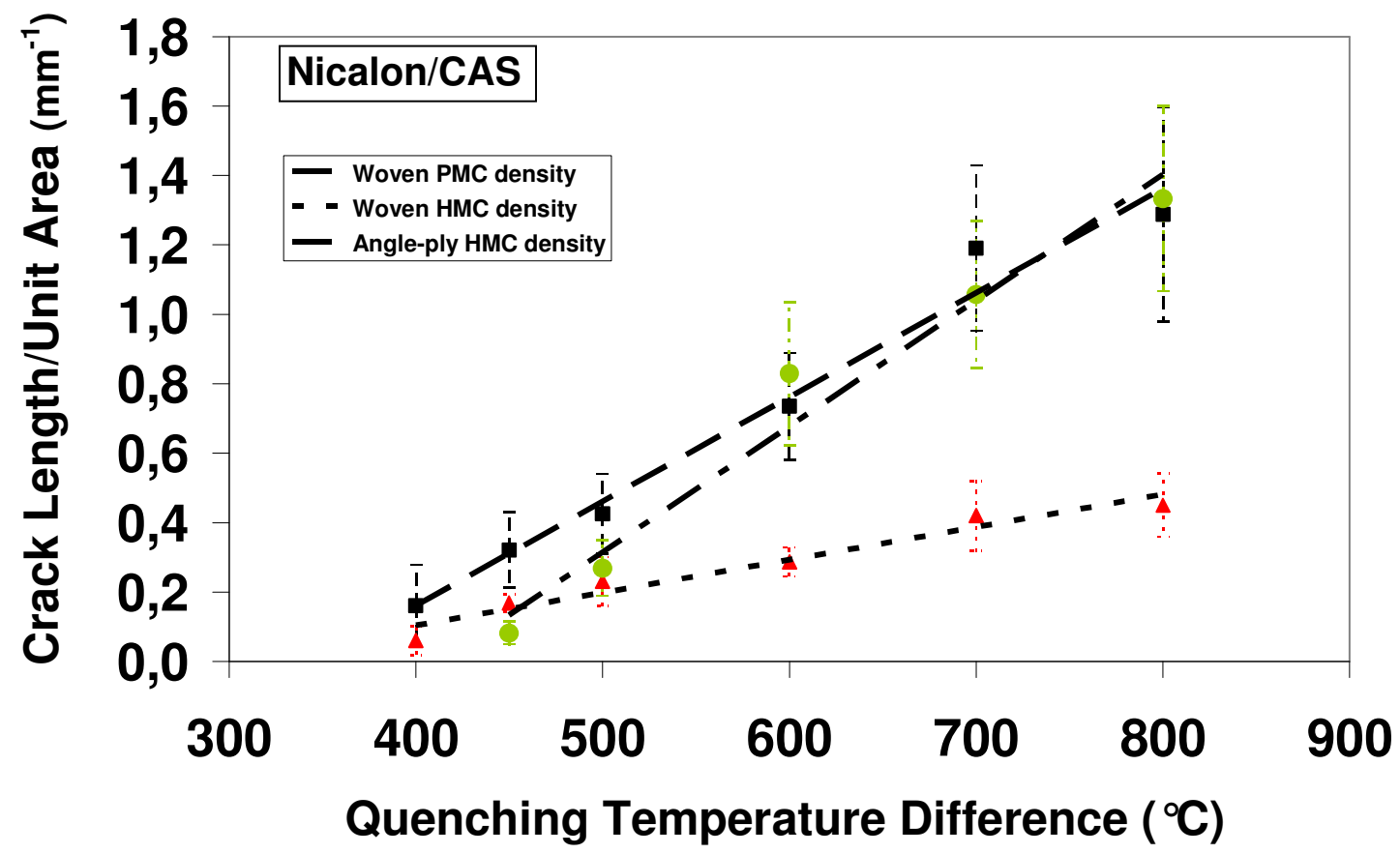

Fig. 4. Crack density plotted against quenching temperature difference $(\Delta T)$ for PMCs and HMCs on PW woven Nicalon/CAS and for HMCs on $\left( \pm 45^{\circ}\right)_{3 \mathrm{~s}}$ Nicalon/CAS.

\subsection{Post-Shock Mechanical Testing}

The stress-strain curves obtained from tensile tests of shocked woven specimens are presented and compared with that of the untreated material in Figure 5. For $\Delta T \leq 500^{\circ} \mathrm{C}$, the curves were identical with that of the unshocked material, and exhibited an initial linear region followed by non-linear behaviour and a final quasi-linear part of reduced gradient up to material failure. Although the curves maintained similar characteristics, i.e. the linear/non-linear/linear pattern, after quenching through $\Delta T>500^{\circ} \mathrm{C}$, a significant drop in the properties of the thermally treated material can be observed. Similar conclusions can be reached by observing the stress-strain curves of shocked samples of 
both materials and that of the untreated ones obtained from flexure tests (Figure 6). All curves exhibit similar characteristics: an initial linear part of steep gradient followed by non-linearity before and after reaching the maximum stress point. However, a gradual reduction in properties is evident for samples shocked through $\Delta T \geq 600$ or $700^{\circ} \mathrm{C}$.

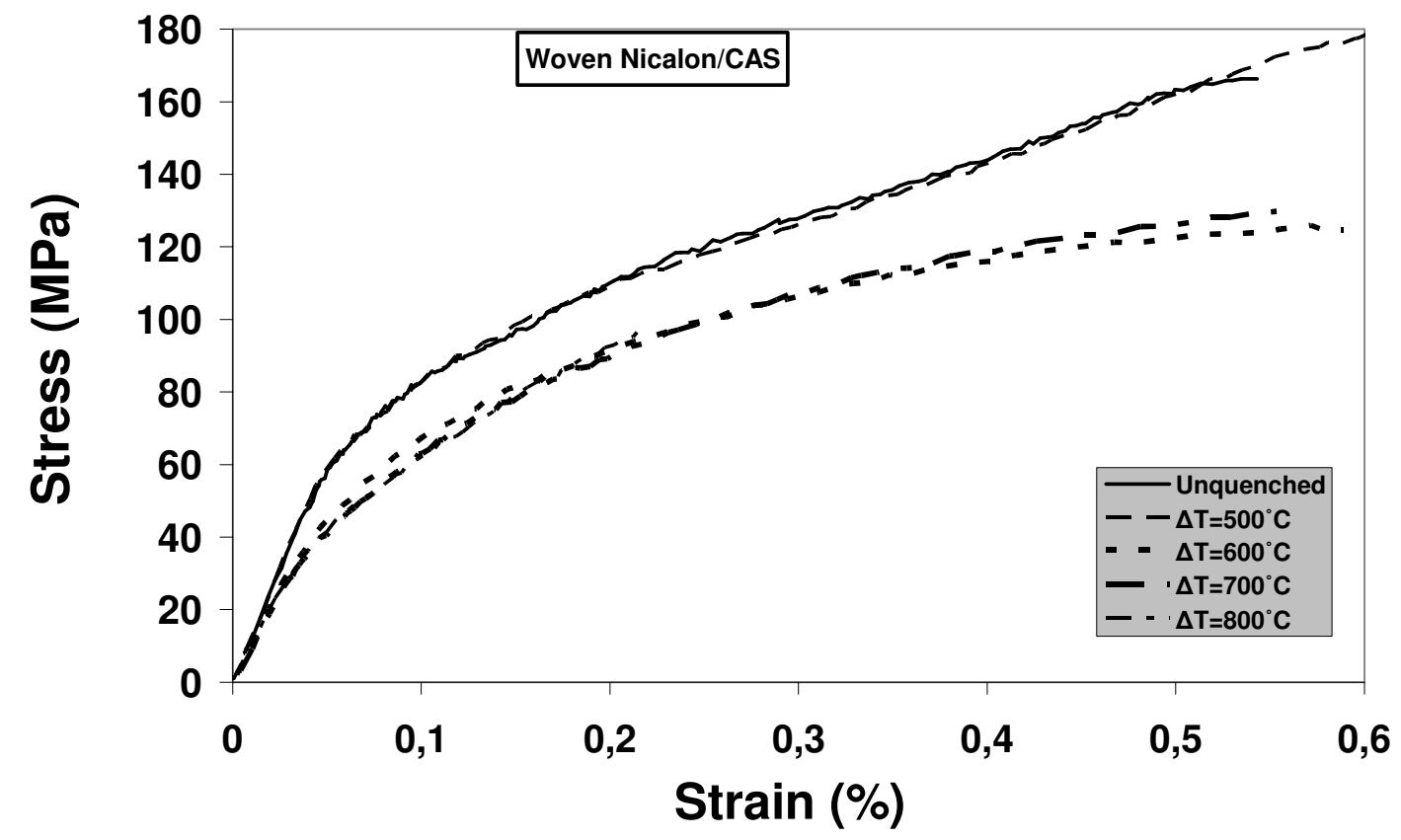

Fig. 5. Tensile stress-strain curves for unquenched (RT) and quenched PW woven $\mathrm{SiC} / \mathrm{CAS}$.

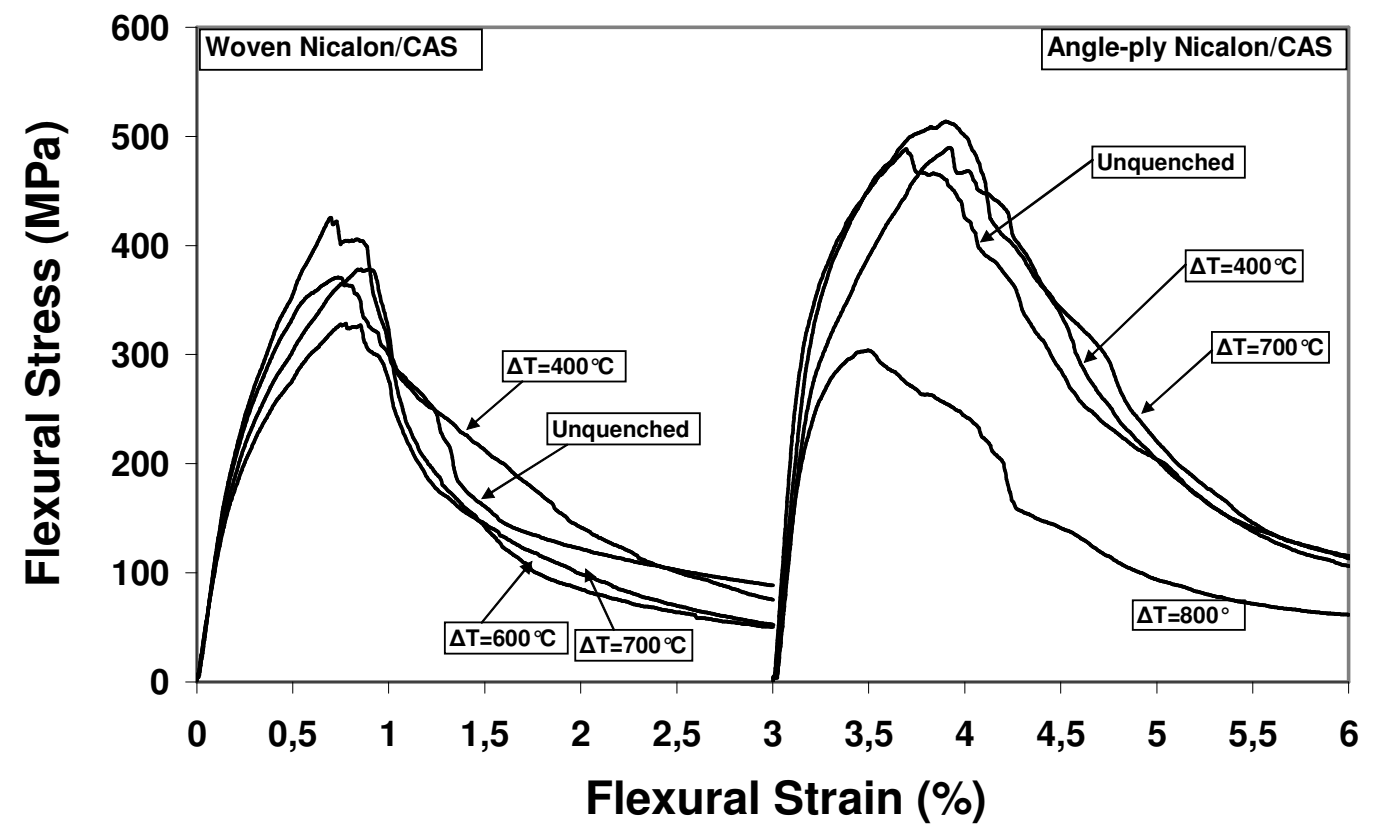

Fig. 6. Flexural stress-strain curves for unquenched and quenched PW woven and $\left( \pm 45^{\circ}\right)_{3 \mathrm{~s}}$ Nicalon/CAS. 
This degrading effect is more evident in Figure 7, where changes in the values of Young's modulus (E), proportional limit stress (PLS), and strength with increasing applied $\Delta T$ are presented. The small number of specimens used to obtain these properties means that the above results should be approached very carefully. However, it is evident that both all properties exhibit a gradual reducing trend for $\Delta T \geq 600^{\circ} \mathrm{C}$.

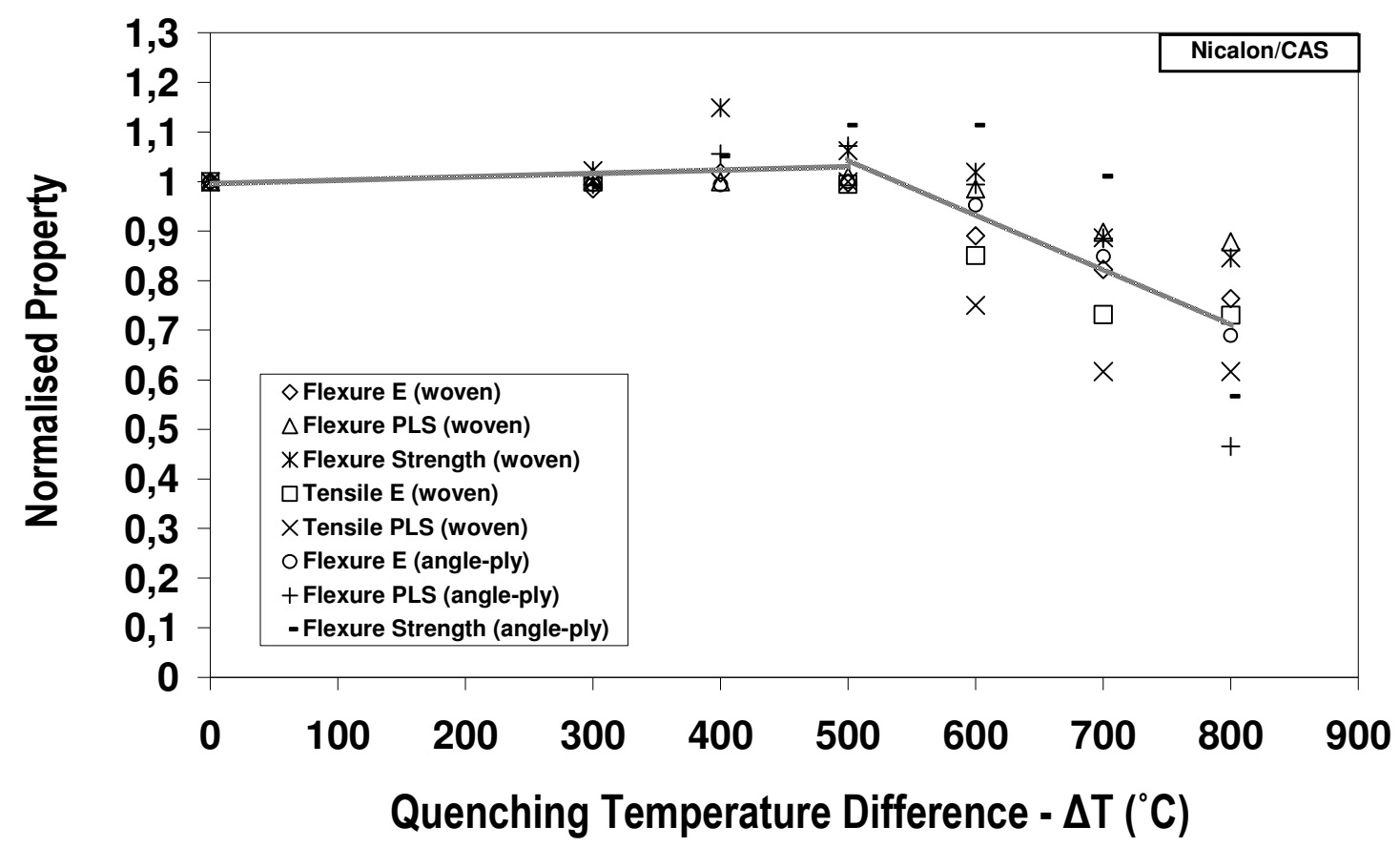

Fig. 7. Effect of increasing severity of applied thermal shock on the tensile and/or flexural Young's modulus (E), proportional limit stress (PLS), and strength of PW woven and $\left( \pm 45^{\circ}\right)_{3 \mathrm{~s}}$ Nicalon/CAS. The general trend of property change is also plotted.

Microscopy of the fracture surfaces of all specimens revealed no changes in failure mode irrespective of thermal history. In tensile samples of the woven laminate, failure coincided with the fracture of fibre bundles (Figure 8); samples of both laminates tested in flexure failed by fracture across the fibre planes (Figure 9). In all cases, the main failure modes were accompanied by extensive pull-out of the reinforcing fibres from the matrix. 


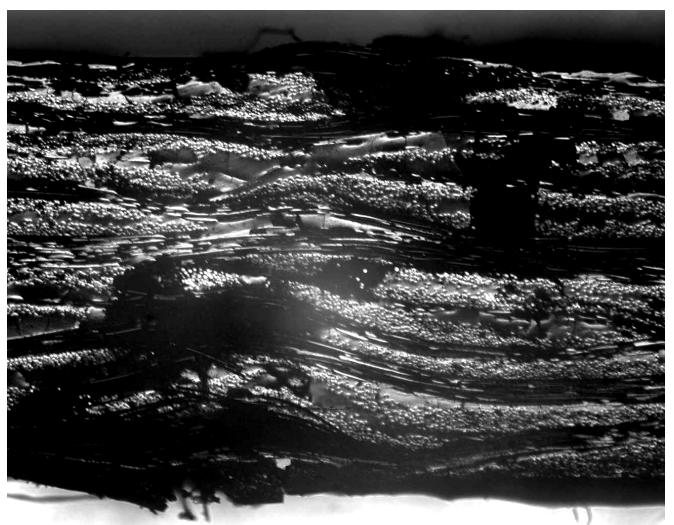

(a)

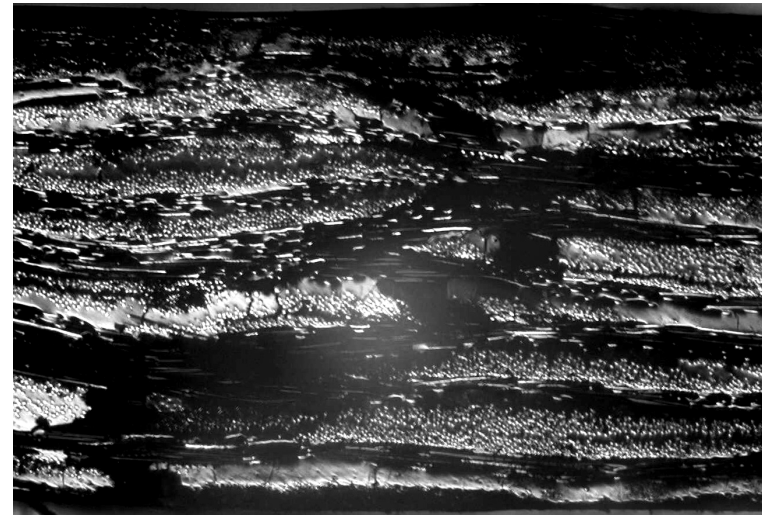

(b)

Fig. 8. The fracture surfaces of (a) unquenched and (b) quenched at $\Delta T=700^{\circ} \mathrm{C} \mathrm{PW}$ Nicalon/CAS specimens after tensile failure. Test samples had a thickness of $2.1 \mathrm{~mm}$.

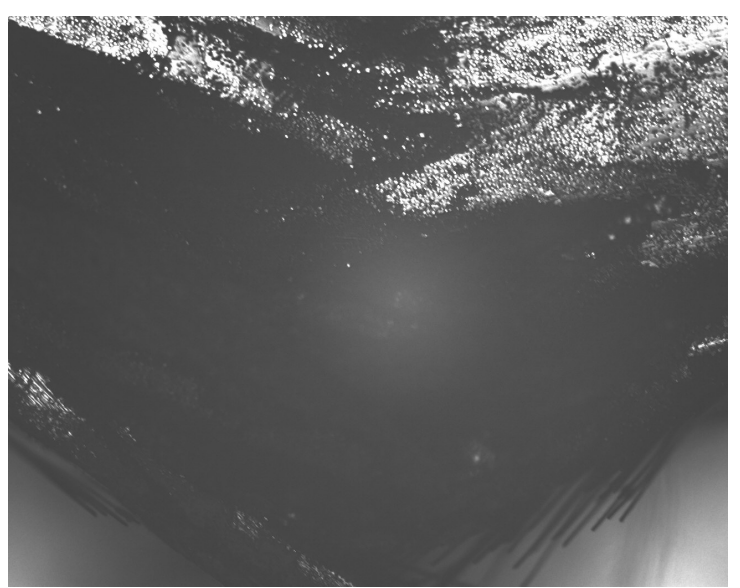

(a)

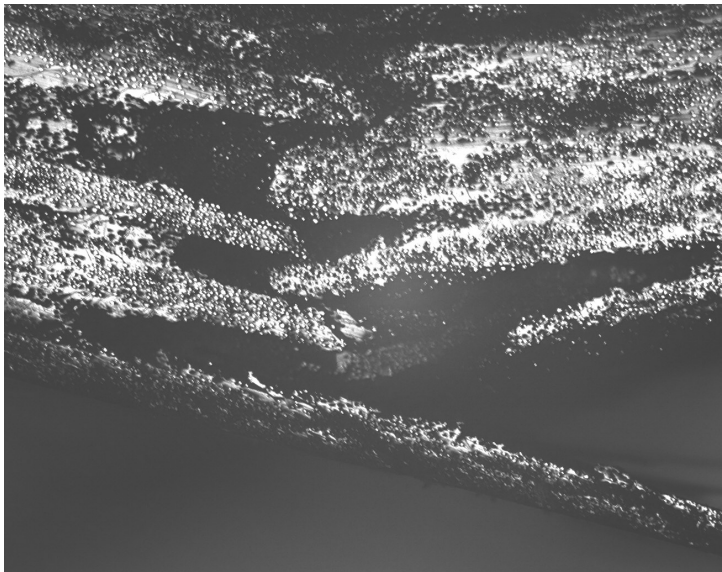

(b)

Fig. 9. The fracture surfaces of (a) unquenched, and (b) quenched at $\Delta T=600^{\circ} \mathrm{C}$ specimens of $\left( \pm 45^{\circ}\right)_{3 \mathrm{~s}}$ Nicalon/CAS tested in flexure.

\section{DISCUSSION}

The main damage mode due to thermal shock in both materials was found to be the same with that for a range of cross-ply systems ${ }^{8,10}$, i.e. matrix cracking. Similarly, in the woven laminate, PMCs were observed in areas of longitudinal plies and HMCs in areas with transverse fibres. The so-called pure matrix plies seem to comprise an independent constituent of this laminate as they developed damage in the form of PMCs. The plies of the angle-ply laminate were found to behave like the transverse plies of the cross-ply and the woven CMCs, as damage only in the form of HMCs appeared. Fibre damage at high $\Delta T$ s on woven specimens soaked for longer times is 
consistent with the observations of Blissett et al. ${ }^{6}$ for UD Nicalon/CAS, and can be associated, as can be seen in the image of Fig. 3(d), with degradation of the carbonaceous fibre-matrix interface due to oxidation processes that allows penetration by an advancing crack and the subsequent fracture of the fibre.

The $\left( \pm 45^{\circ}\right)_{3 s}$ and the PW woven Nicalon/CAS laminates exhibited thermal shock resistance similar to the multi-layered cross-ply laminates ${ }^{10}$ of comparable thickness. Small differences observed in the value of $\Delta T_{\mathrm{c}}$ should be assigned to small microstructural variations due to the reduced individual ply thickness and the existence of matrix-rich plies in the woven laminate, and the existence of $45^{\circ}$ plies in the angleply laminate. Similarly, damage originated at, or close to, the centreline of the surface under observation and extended, at higher $\Delta T \mathrm{~s}$, towards the top and bottom edges. However, PMCs in the woven material, appeared to be more evenly distributed on the surface. This may be the result of the undulating nature of the various 'plies' that compose this system, which probably distribute the shock-induced stresses over a larger surface area.

Although the morphology of PMCs and HMCs in both materials exhibited similar trends with those observed in their multi-layered cross-ply counterparts (i.e. PMCs increased significantly in number but not in depth, HMCs penetrated increasingly the matrix ${ }^{10}$ ) with the application of more severe shocks, there are reasons to believe that the woven configuration shows better behaviour under conditions of thermal shock. First, a comparison of PMC and HMC densities at each $\Delta T$ with those of waterquenched simple and multi-layered cross-ply laminates ${ }^{10}$ (Figures 10(a) and (b)), reveals that, at least as far as crack length on the quenched surface is concerned, the angle-ply laminate shows comparable crack extent while the woven material exhibits 
much lower crack densities for both PMCs and HMCs. Actually, they are comparable with those of the much thinner simple cross-ply laminates. This, apart from the different ply configuration of the woven $\mathrm{CMC}$, can be assigned to the undulating nature of the different areas it comprises. PMCs are distributed in a larger area of the surface (as mentioned previously) while HMCs were observed to arrest when they encountered areas of different composition. Since the length of the transverse plies in woven Nicalon/CAS is nominally much smaller than that in simple and multi-layered cross-ply materials, the average length that HMCs can propagate is restricted. Only at the highest temperature differential $\left(\Delta T=700-800^{\circ} \mathrm{C}\right)$ and in small number of samples, HMCs were seen to extend into other plies. In addition, the presence of other areas on the path of HMCs that can act as 'crack-stoppers' leads to the suggestion that a similar effect may be taking place along the depth direction as well. Thus, the extent HMCs propagate through the matrix of the woven material should be reduced compared with the multilayered cross-ply and the angle-ply laminates.

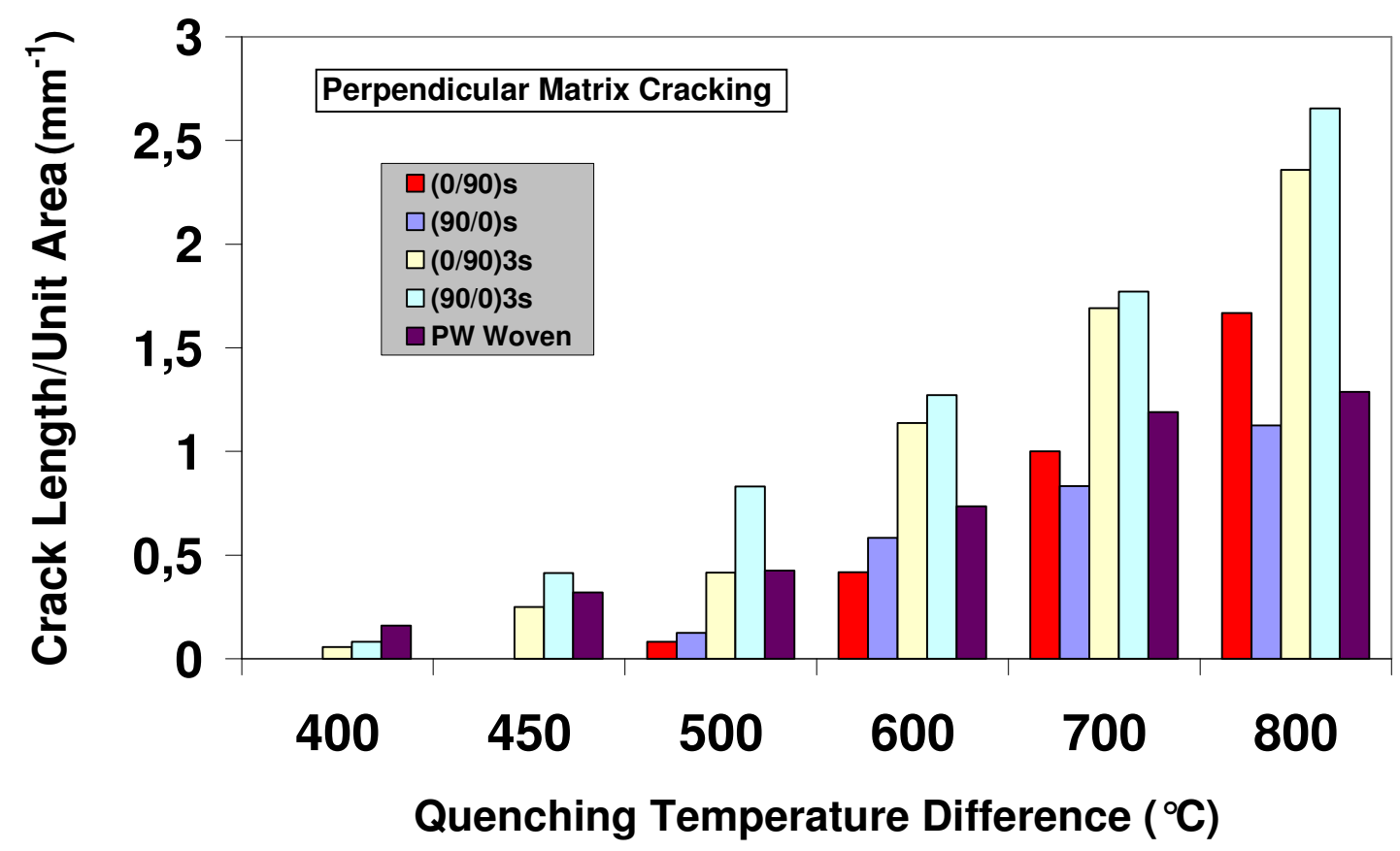

(a) 


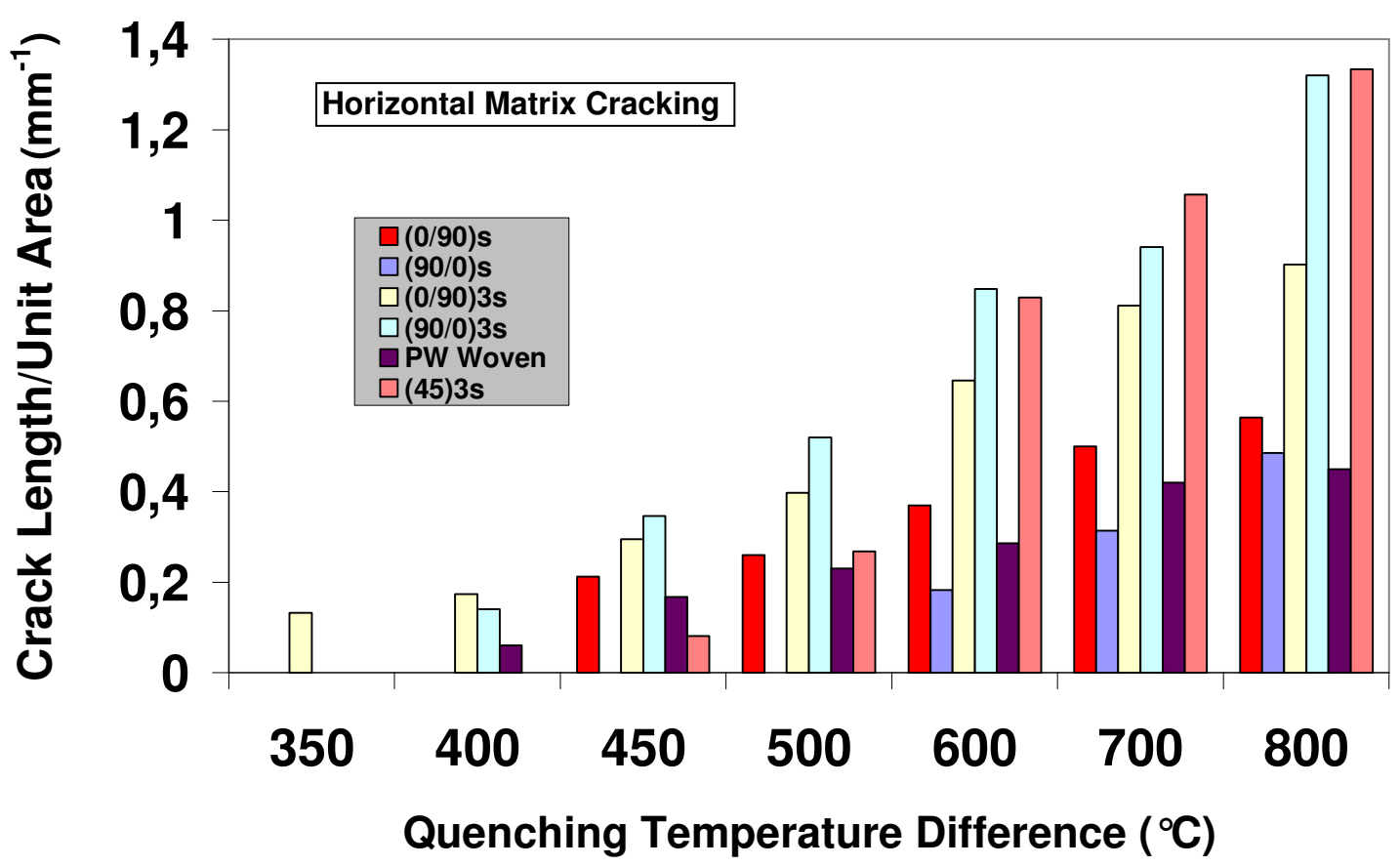

(b)

Fig. 10. Comparison at various $\Delta T$ s of (a) PMC density, and (b) HMC density, for a range of Nicalon/CAS laminates

The trends of the property changes with increasing $\Delta T$ determined from tensile and flexural tests were found to be similar for both laminates. The materials seemed not to be affected by the application of shocks up to $\Delta T=500^{\circ} \mathrm{C}$. Application of higher $\Delta T \mathrm{~s}$ resulted in a gradual reduction of all properties monitored, which is in agreement with previously proposed theoretical arguments ${ }^{13}$. It was also noted that the materials exhibited true 'composite' behaviour irrespective of testing method utilised and severity of thermal treatment. This is evident in the non-linearity of the stress-strain curves obtained, which are a characteristic of this class of materials, as well as in the extensive pull-out of the fibres from the matrix observed on the fracture surfaces of failed samples. In addition, the failure modes of treated and untreated samples were identical. This shows that damage due to thermal shock alone does not alter the general behaviour 
of the materials despite having a detrimental effect on their properties. By contrast, several authors have reported changes in failure mode under flexure after thermal shock $^{3,5}$. This discrepancy may be attributed to differences in interlaminar shear strength between the materials that renders some more susceptible to thermal shock damage and results in a change of failure mode. In addition, extra care was taken in this investigation to separate thermal shock effects from oxidation-related material degradation. As a result, the samples tested did not exhibit any visible chemical degradation even after high-temperature exposure. Degradation of the fibre-matrix interface in this class of materials is usually correlated with changes in failure mode as the material becomes more brittle.

Another observation that can be made is that the critical temperature differential for the onset of cracking in both materials does not coincide with the respective temperature differential for which property degradation begins. More specifically, damage appears for $\Delta T=400-450^{\circ} \mathrm{C}$ while property degradation commences at $\Delta T=600^{\circ} \mathrm{C}$. This is a welldocumented feature of this class of materials as it has also been reported by a number of other authors ${ }^{3,7}$. It shows that fibre-reinforced CMCs, in contrast to their monolithic counterparts, can sustain a certain amount of damage before their properties are affected and, thus, exhibit superior behaviour under thermal shock conditions. In addition, it must be noted that the damage mode responsible for property reductions in both materials appears to be HMCs, which, at a particular $\Delta T$ that coincides with the onset of property changes, were observed to grow deep into the material. HMCs were the sole 'macroscopic' form of damage in the angle-ply material, while damage in the form of PMCs in the woven material remained surface features at all temperature differentials.

\section{CONCLUDING REMARKS}


The thermal shock behaviour of two Nicalon/CAS laminates, a $\left( \pm 45^{\circ}\right)_{3 \mathrm{~s}}$ and a plainweave woven, has been studied. The main damage modes were found to be similar to those observed in cross-ply CMCs with the same constituents, and comprised matrix cracks of various orientations and fibre breaks due to high-temperature microstructural degradation. However, the extent of damage accumulation on the woven material was found to be significantly lower. Mechanical testing of thermally-shocked specimens revealed a gradual reduction in properties. However, the onset of property reduction was found to be higher than the onset of damage on material surfaces and coincided with significant changes in the morphology of one mode of damage that penetrated into the bulk of the materials.

\section{Acknowledgement}

The authors would like to thank Rolls-Royce plc. for the provision of experimental materials. CK acknowledges financial support from the Engineering and Physical Sciences Research Council (UK) and the 'Alexander S. Onassis' Public Benefit Foundation. We would also like to thank Dr. Hal Belmonte, Dr. Brian Le Page and, particularly, Mr. Mike Parker, Mr. Peter Haynes and Dr. Nick Ludford for technical assistance and many helpful discussions.

\section{References}

1. H. Wang and R. N. Singh, Int. Mat. Rev. 39 (1994) 228

2. C. Kastritseas, P. A. Smith and J. A. Yeomans, in "Ceramic Matrix Composites: Microstructure-Property Relationship" (Woodhead Publishing Ltd., 2006)

3. H. Wang, R. N. Singh and R. A. Lowden R A, J. Am. Ceram. Soc. 79(7) (1996) 1783 
4. J. E. Webb, R. N. Singh and R. A. Lowden, J. Am. Ceram. Soc. 79(11) (1996) 2857

5. Y. Kagawa, N. Kurosawa and T. Kishi, J. Mater. Sci. 28 (1993) 735

6. M. J. Blissett, P. A. Smith and J. A. Yeomans, J. Mater. Sci. 32 (1997) 317

7. A. R. Boccaccini, D. H. Pearce, J. Janczak, W. Beier and C. B. Ponton, Mat. Sci. Tech. 13 (1997) 852

8. M. J. Blissett, P. A. Smith and J. A. Yeomans, J. Mater. Sci. 33 (1998) 4181

9. C. Kastritseas, P. A. Smith and J. A. Yeomans, Comp. Sci. Tech. 65 (2005) 1880

10. C. Kastritseas, P. A. Smith and J. A. Yeomans, J. Mater. Sci., 41 (2006) 951

11. S. Graham, D. L. McDowell, E. Lara-Curzio, R. B. Dinwiddie, H. Wang and W. Porter, J. Comp. Mater. 37(1) (2003) 73

12. S. M. Bleay, V. D. Scott, B. Harris, R. G. Cooke and F. A. Habib, J. Mater. Sci., 27 (1992) 2811

13. A. R. Boccaccini, Scripta Mater. 38(8) (1998) 1211 